\title{
Análise das Convenções sobre Restituição Internacional de Crianças Indevidamente Transportadas ou Retidas à Luz da Teoria dos Regimes Internacionais
}

\section{Analysis of the Conventions on International Restitution of Children Wrongfully Retained or Removed Under the Light of the International Regime Theory}

\author{
Rachel de Oliveira Lopes \\ Universidade Católica de Santos, Santos - SP, Brasil
}

José Augusto Fontoura Costa

Faculdade de Direito de Sorocaba, Sorocaba - SP, Brasil

Resumo: Neste artigo se examina a formação de regimes que tratam da subtração internacional de crianças, a partir da teoria das relações internacionais, demonstrando ser adequada a cooperação mesmo em hipóteses alheias a questões econômicas ou de segurança. Adota-se o método qualitativo, partindo do exame da formação dos regimes tratados, em seguida faz-se a análise dos modelos teóricos das relações internacionais e, finalmente, realiza-se o estudo da constituição e manutenção dos regimes, sob a perspectiva de cada um dos modelos teóricos, revelando-se ao final que a teoria das relações internacionais fornece instrumentos de fomento à cooperação mesmo em temas marginais ao lucro ou ao poder.

Palavras-chave: Regimes Internacionais. Cooperação. Sequestro. Crianças. Menores.
Abstract: This paper aims to examine the formation of international regimes on the civil aspects of children abduction, from the theory of international relations, which is shown adequate to justify cooperation even in cases outside the economic or security issues. From the qualitative method, the article firstly addresses the formation of the examined regimes; next it focuses in the exam of the theoretical models of international relation; and finally it focuses in the analysis of the constitution and maintenance of the regimes, revealing in the end that the theory of international relations provides promotion instruments for cooperation even on marginal issues to profit or power.

Keywords: International Regimes. Cooperation. Children. Abduction. 


\section{Introdução}

Este artigo tem por finalidade analisar, mediante exame do sistema internacional de repatriação de crianças, o uso das teorias dos regimes internacionais como instrumento de compreensão e avaliação de ferramentas de cooperação jurídica internacional. Para tanto, realiza (a) uma breve exposição da problemática e dos instrumentos internacionais de restituição de crianças ilicitamente removidas, (b) uma breve síntese das teorias dos regimes internacionais e (c) a discussão de sua aplicabilidade como modelo de análise para outros âmbitos da cooperação jurídica, bem como para sua compreensão em abstrato.

O problema a ser abordado é o de como as teorias dos regimes internacionais, voltadas a explicar a cooperação em contextos de conflitos presumidos, são necessárias e úteis para a compreensão de áreas em que nem a segurança, nem a riqueza dos Estados envolvidos são afetadas significativamente.

De fato, a cooperação jurídica afeta profundamente o exercício de poderes do Estado, sendo conceitualmente profunda, na medida em que atrela elementos da própria prestação jurisdicional a acordos internacionalmente vinculantes. Entretanto, dela não decorrem quaisquer efeitos necessários que afetem diretamente a defesa ou a economia, não afetando, por exemplo, a fronteira de possibilidade de produção de segurança e riqueza (guns v. butter) proposta por Robert Gilpin (1981) ou posicionando a questão na tensão entre realismo e neoliberalismo institucional, nos termos de Arthur Stein (1990, 2008).

Como, no caso a ser estudado, a expedita devolução de crianças, ilicitamente removidas do titular de sua guarda em país estrangeiro, não pode ser vista como algo que afete, de algum modo, a segurança do Estado e, tampouco, implique consequências econômicas significativas. Qual seria, então, a contribuição resultante de seu estudo mediante a aplicação das teorias de regimes internacionais?

Embora possa fazer sentido em um contexto ético ou axiológico, a resposta "pelo bem das crianças" não é palatável para os gostos refinados dos teóricos das Relações Internacionais. É preciso, de algum modo, 
compreender porque o Estado atuaria internacionalmente se não é para obter maior poder ou riqueza ou, alternativamente, porque a restituição de crianças poderia gerar poder ou lucro. $\mathrm{O}$ presente artigo opta pela segunda linha de explicação a partir da seguinte hipótese: embora não existam efeitos imediatos de monta nos âmbitos da defesa ou da economia, o robustecimento das relações entre os Estados, proporcionado por ações de cooperação jurídica, torna a cooperação mais provável em outras áreas, à medida que proporciona maior confiança, estabelece canais regulares de comunicação e incrementa potenciais prejuízos resultantes do descumprimento de outros regimes.

\section{Breves Considerações acerca da Formação dos Regimes Internacionais sobre Crianças Indevidamente Transportadas ou Retidas}

O processo de globalização, dentre outras consequências, possibilitou um incremento no número de migrações internacionais e ensejou a alteração do domicílio e da residência de famílias já previamente constituídas, ou a constituição de laços familiares entre pessoas de diferentes nacionalidades. Por outro lado, aliado à ocorrência comum de desavenças matrimoniais e de desconstituição destes laços, tal fato também deu ensejo à remoção ilícita ou à retenção após transporte indevido das crianças frutos de tais relacionamentos, para países estranhos àqueles em que estava estabelecida a sua residência habitual.

Em termos gerais, a intenção daquele que subtrai ou retém ilegalmente a criança é a de instaurar relação processual no país de refúgio, a fim de afastar os direitos de custódia do (outro) detentor que remanesce no país de origem, estabelecendo a exclusividade de tal exercício. É tema que pertence à seara do direito de família e do direito processual, pois diz respeito aos "[...] aspectos civis da transferência ou retenção ilícitas de uma criança, perpetrada, em regra, por um de seus genitores, em infração ao 'direito convencional de guarda', titularizado pelo outro genitor (ou por ambos).” (MARTINS, 2013, p. 56). 
A questão, na medida em que se refere a relações privadas entre nacionais de diferentes Estados, acaba tangenciando mais de um ordenamento jurídico e promovendo a insuficiência do ajuste de conduta por atos apenas de um governo estatal, limitado territorialmente. Com efeito, a prestação de tutela jurisdicional que altera artificialmente os direitos de custódia, legal e naturalmente exercidos em outro Estado, alcança tanto o ordenamento jurídico ao qual estaria submetido o subtrator (e cuja aplicação é por ele invocada), quanto o ordenamento jurídico daquele que foi deixado para trás, uma vez que cada uma das partes, seja por invocação da nacionalidade, seja por invocação do domicílio, possui argumentos de defesa da aplicação das normas específicas, pelo que estabelecido conflito em termos de poder estatal, bem como a necessidade de homogeneidade de condutas para a solução de tal conflito.

Considere-se que, ausente a regulação comum, a tendência judicial era a de, após moroso procedimento, garantir os pretensos direitos daquele nacional que se encontrava de posse da criança subtraída, mormente porque exercida a pretensão sob argumentos culturais e sociais específicos, comuns ao do julgador, que procedia assim à prestação de tutela respaldada em valores normativos comunitários ${ }^{1}$. Olvidavam-se aí os valores comunitários da outra parte e do ordenamento jurídico ao qual estava submetida, não menos importantes do que aqueles do subtrator; olvidava-se o fato de que o bem-estar da criança subtraída - pelo menos naquele momento - estava muito mais relacionado à estabilidade das relações violentamente alteradas, do que à companhia de qualquer dos solicitantes; e olvidava-se a artificialidade da relação processual constituída.

Por outro lado, também não se pode negar que a subtração ou retenção indevida de crianças nem sempre está relacionada exclusivamente ao simples anseio de custódia ou guarda exclusiva com vistas à sua manu-

\footnotetext{
${ }^{1}$ Eliza Peréz-Vera (1981, p. 431), no relatório explicativo da Convenção da Haia de 1980 sobre o Sequestro Internacional de Crianças, destaca: "It can happen that such a decision is the most just, but we cannot ignore the fact that recourse by internal authorities to such a notion involves the risk of their expressing particular cultural, social etc. attitudes which themselves derive from a given national community and thus basically imposing their own subjective value judgments upon the national community from which the child has recently been snatched".
} 
tenção no Estado de que é nacional o subtrator, mas pode ter como causa eventos mais graves, como o é a violência doméstica, por exemplo. Em tais hipóteses, a prestação da tutela jurisdicional no sentido do afastamento da criança daquele que contra esta exercia tal violência poderia até se demonstrar legítima, mas, ainda assim, o conflito de interesses estatais se configura, na medida em que a competência jurisdicional remanesce constituída de modo artificial e mediante o uso da força.

Postos tais termos, parecia clara a necessidade de se estabelecerem padrões de comportamento judicial capazes de inibir a conduta do subtrator violento ou de homogeneizar as decisões para as hipóteses excepcionais em que a subtração fosse legítima. Com efeito, ainda que cada ordenamento jurídico pudesse estabelecer regras de aplicabilidade de direito privado estrangeiro, não havia garantias de que tal aplicabilidade fosse homogênea a ponto de afetar comportamentos e resultados de um modo geral, principalmente quando se transita na seara do direito civil, cujas disposições estão sempre atreladas à cultura de cada povo (DOLINGER, 2011, p 164).

Tenha-se, ademais, que a questão principal em torno da situação fática narrada não diz respeito à verificação do preenchimento dos requisitos necessários ao exercício da guarda ou da custódia de uma criança, ou ao exercício do direito de visita, mas se refere à neutralização da ação daquele que, violando o compartilhamento de direitos ou o exercício individual de tais direitos por segunda pessoa, altera a estabilidade física e emocional de uma criança e viola o princípio do juiz natural. Nessa hipótese, um resultado ótimo somente poderia ser alcançado a partir de ações coordenadas entre Estados.

Foi nesse sentido que a situação fática descrita passou a se constituir no objeto da Convenção da Haia de 1980, sobre os Aspectos Civis do Sequestro Internacional de Crianças e, posteriormente, da Convenção Interamericana Sobre Restituição Internacional de Menores, que estabeleceram a configuração de regimes internacionais (o segundo, mais regionalizado) sobre restituição de crianças indevidamente retidas ou transportadas.

Estabeleceu-se ali que a decisão final em torno da custódia da criança indevidamente transportada ou retida seria apenas tomada após a sua 
restituição ao país de origem, e pelas autoridades daquele lugar. Deste modo, a conduta do subtrator remanesce sem os efeitos jurídicos que visava constituir. Por outro lado, estabeleceram-se ali também os meios de cooperação administrativa e judiciária, de modo a tornar inclusive sem efeitos práticos tal conduta, mediante a localização da criança, a garantia do direito de acesso da outra parte, e mediante a imediata restituição.

Postos tais termos, fica claro que os regimes dos quais aqui se trata passam à margem de questões de segurança militar ou de poder econômico, pelo que impende investigar qual então seria o fundamento para a cooperação ali estabelecida, quando, seja sob pressupostos realistas, seja sob pressupostos funcionalistas, as relações internacionais se travam entre atores auto interessados que se comportam de modo calculado e intencional$^{2}$ (STEIN, 1993, p. 10). Como se justificaria a estabilidade das relações convencionais, se sob a perspectiva realista as instituições não são relevantes, na medida em que sobrepostas pelos interesses dos Estados, sempre voltados para lucro e segurança militar; e se também sob a perspectiva liberal os atores se comportam de modo a maximizar os seus próprios resultados (STEIN, 1993, p. 46)? Por outro lado, será que mesmo ao largo de questões de força e poder, os regimes internacionais de que se trata aqui não teriam o condão de gerar, ainda que por via indireta, ganhos econômicos e de segurança para os Estados que a eles aderem?

A resposta passa obrigatoriamente pelo exame do conceito de regimes internacionais e dos modelos de análise dispostos pela teoria das relações internacionais, a seguir procedida.

\section{Conceito e Modelos de Análise da Formação dos Regimes In- ternacionais}

O artigo Structural Causes and Regime Consequences: regimes as intervening variables, originariamente publicado por Stephen Krasner na revista International Organization, é marco conceitual da teoria dos regimes internacionais. De fato, ainda que a origem da teoria esteja situada

${ }^{2}$ No original: “[...] both realism and liberalism presume self-interested, purposive, and calculated behavior" (STEIN, 1993, p. 10). 
na década de $1970^{3}$, o conceito de Krasner (1982, p. 186) disseminou-se no estudo das relações internacionais e é dos mais aplicados, na medida em que se adapta tanto aos modelos de análise estruturalistas, quanto aos pressupostos funcionalistas.

Dali se depreendem quatro elementos cardeais: princípios, normas, regras e procedimentos de tomada de decisão - não necessariamente cumulativos - que constituem a base de convergência dos atores decisórios em determinada área temática, com vistas à solução de conflitos. Esclarece o autor que os princípios são crenças de fato, causas e retidão (conteúdo moral); as normas são padrões de comportamento definidos em termos de direitos e obrigações; as regras são prescrições ou proscrições especificas para a ação; e que os procedimentos para tomada de decisões são práticas predominantes para fazer e implementar as escolhas coletivas ${ }^{4}$.

Os regimes internacionais surgem assim como "[...] variáveis intervenientes entre os fatores causais básicos de um lado e resultados e comportamentos de outro [...]"5, na esteira do pensamento de Krasner (1982, p. 185), que os define como "[...] princípios, normas, regras e procedi-

${ }^{3}$ No o artigo International Responses to Technology: concepts and trends, de John Gerard Ruggie (1975) associa às mudanças tecnológicas a necessidade de alteração da organização internacional, a partir das instituições.

${ }^{4}$ No original: "Principles are beliefs of fact, causation and rectitude. Norms are standards of behavior defined in terms of rights and obligations. Rules are specific prescriptions or proscriptions for action. Decision-making procedures are prevailing practices for making and implementing collective choice".

${ }^{5}$ No original: "As a starting point, regimes have been conceptualized as intervening variables standing between basic casual factors on the one hand and outcomes and behavior on the other". O autor esclarece mais à frente quais seriam os parâmetros do realismo: "If human affairs are indeed characterized by groupism, egoism, and powercentrism, then politics is likely to be conflictual unless there is some central authority to enforce order. When no authority exists that can enforce agreements - "anarchy" - then any state can resort to force to get what it wants. Even if a state can be fairly sure that no other state will take up arms today, there is no guarantee against the possibility that one might do so tomorrow. Because no state can rule out this prospect, states tend to arm themselves against this contingency. With all states thus armed, politics takes on a different cast. Disputes that would be easy to settle if states could rely on some higher authority to enforce an agreement can escalate to war in the absence of such authority. The 
mentos de tomada de decisões em torno dos quais convergem as expectativas dos atores em determinada área das relações internacionais"\%.

O dissenso doutrinário, contudo, não se situa na conceituação, mas em torno dos padrões de conflito ou de cooperação e de como a prevalência de um ou de outro destes padrões pode ou não dar ensejo à formação e à manutenção de regimes internacionais.

Arthur Stein (1993, p. 4) destaca que o realismo é a perspectiva dominante no campo das relações internacionais. Para os realistas, "[...] a intersecção de grupismo e egoísmo em um ambiente de anarquia, faz das relações internacionais uma política de poder e segurança [...]"7 (WOHLFORTH, 2002, p. 134), na qual “[...] os Estados são únicos protagonistas importantes, a força militar é o instrumento dominante e a segurança é a meta dominante" (NYE, 2009, p. 264). O argumento teórico é, portanto, o conflito e, sendo assim, os regimes internacionais seriam de pouca relevância, na medida em que eventual convergência seria sempre ultrapassada em benefício de interesses Estatais específicos. Quaisquer princípios, normas, regras ou procedimentos estabelecidos seriam facilmente violados em hipóteses de ameaça, e diante da inexistência de autoridade superior capaz de impor a ordem.

Nessa mesma linha, cabe também destaque ao recorte estruturalista, em que se ressalta a importância da participação de atores hegemônicos, sem os quais um regime internacional não poderia se manter, na medida em que apenas estes seriam capazes de fornecer os bens necessários para tanto (KRASNER, 1982). Nesse sentido, os regimes não seriam resultado de consenso, mas fruto de imposição; e não se manteriam com a retirada do ator hegemônico.

Teóricos de viés mais cooperacional, todavia, têm observado que “[...] há momentos em que o cálculo racional egoísta leva atores a abando-

signature realist argument is therefore that anarchy renders states' security problematic and potentially conflictual, and is a key underlying cause of war. (p. 135)"

${ }^{6}$ No original: "International regimes are defied as principles, norms, rules and decisionmaking procedures around which actor expectations converge in a given issue-area".

${ }^{7}$ No original: "The intersection of groupism and egoism in an environment of anarchy makes international relations, regrettably, largely a politics of power and security". 
nar a tomada de decisão independente em favor da tomada de decisão conjunta $^{8 "}$ (STEIN, 1993, p. 45). Para estes, o conflito seria fruto da falta de informação, e da compreensão equivocada dos fatos, situação contornável a partir de instituições e, consequentemente, da constituição de regimes.

Ressalvem-se aqui, contudo, os partidários do liberalismo que, muito embora encontrem fundamento para a cooperação no sistema econômico - por acreditarem que um ambiente de livre mercado teria o efeito de ordenar os relacionamentos - têm por prescindíveis as instituições, na medida em que a própria ordem disposta para a economia é que serviria de esteio à estabilidade de práticas cooperativas.

Não é este, todavia, o raciocínio externado a partir das teorias funcionalistas, cujo foco é a aptidão dos regimes em cumprir dadas funções, e não a definição dos seus efeitos. Neste sentido, para os partidários do neoliberalismo institucional, as instituições executam tarefas importantes, ao permitir a cooperação entre Estados, reduzir os custos da elaboração, do monitoramento e da aplicação de regras - os custos de transação -, possibilitar o fluxo de informações e facilitar o compromisso a partir da reciprocidade (o que inclui tanto as ameaças de retaliação quanto promessas de cooperação recíproca) e do zelo pela reputação (KEOHANE, 2002, p. 3) ${ }^{9}$.

Robert Axelrod demonstra em The Evolution of Cooperation (1984), sob a perspectiva da teoria dos jogos ${ }^{10}$, que, em casos de contínua interação entre atores, inexistindo o conhecimento prévio acerca do

\footnotetext{
${ }^{8}$ No original: "There are times when rational self-interested calculation leads actors to abandon independent decision making in favor of joint decision making".

${ }^{9}$ Keohane (2002, p. 3) destaca: "I argued that institutions perform important tasks for states, enabling them to cooperate. In particular, institutions reduce the costs of making, monitoring, and enforcing rules - transaction costs - provide information, and facilitate the making of credible commitments. In this theory, the principal guarantors of compliance with commitment are reciprocity (including both threats of retaliation and promises of reciprocal cooperation) and reputation".

10 Como já informado em obra anterior (GONÇALVES; COSTA, 2011, p. 128), "Pindicyck e Rubinfeld (1994) identificam a questão principal da teoria dos jogos como referente a de que forma - com base na crença na racionalidade econômica dos concorrentes e estabelecida a finalidade maximização dos lucros - atores econômicos se perguntam como deveriam levar em conta o possível comportamento alheio ao tomar as próprias decisões”. Nesse sentido, “[a] simples substituição de 'lucros' por 'poder'
} 
termo final de tal interação (sombra do futuro), em ambiente de informação transparente e facilitada que favoreça o conhecimento mútuo das estratégias e estabeleça a confiança e a parceria, mantida a lealdade, ou a retaliação para os casos de traição, ou mesmo o perdão para quem deseja mudar de estratégia, práticas cooperativas podem implementar ganhos para todos os participantes.

Sendo assim, ainda que se considere que os atores decisórios são racionais e buscam a maximização dos seus ganhos, há hipóteses em que ajustamentos de conduta podem ser mais benéficos do que a atuação individual.

Dentre os funcionalistas cabe também destaque ao neorrealismo, que ultrapassa o pensamento de Hans Morgenthau (2003 [1948]) para considerar que há outras áreas da política, além da concentração e manutenção do poder, em que é possível haver cooperação. Para estes, todavia, a intenção cooperativa é sempre a busca de um ganho relativo, por certo maior em relação aos demais atores, contrapondo-se, assim, ao neoliberalismo institucional que assume a possibilidade de ganhos absolutos ao conjunto.

Indispensável, por outro lado, fazer também menção à teoria construtivista que, rompendo com os pressupostos materialistas do realismo, assume que as relações entre os atores ou o comportamento destes quanto a determinados objetos se justifica a partir do significado que os outros atores ou que estes objetos possuem, consideradas as próprias identidades, as crenças compartilhadas e as práticas de que participam (HURD, 2008, p. 299). Com tais pressupostos também se apartam do racionalismo institucionalista, na medida em que, muito embora não desconsiderem a intenção estatal de satisfação dos próprios interesses e necessidades, têm por mais relevante esclarecer o modo e a razão pelos quais tais interesses e necessidades se formam.

Nesse sentido, para os construtivistas as relações políticas seriam construções sociais e não apenas relações de poder nas quais "[...] objetos materiais como bombas, óleo ou pessoas têm um efeito direto sobre os resultados, sem qualquer mediação de ideias [...]"

e de 'racionalidade econômica' por 'percepção realista' seria suficiente para transpor o problema central para o âmbito das relações internacionais". 
(HURD, 2008, p. 299); nem se constituem em mero cálculo instrumental de interesses, sem influências do processo social. As instituições, assim, ao mesmo tempo em que construídas a partir das ações estatais, também contribuiriam para "definir, socializar e influenciar os Estados" (HURD, 2008, p. 303), determinando práticas cooperativas para o futuro.

Parece claro até aqui - e sem desconsiderar o alerta de preponderância feito por Arthur Stein - que mesmo que a escola realista atue como um first cut, na delimitação da área temática, há outras construções teóricas das relações internacionais que, não sendo excludentes entre si, também fornecem e explicam os parâmetros de tomada de decisão da política internacional. Keohane (2002, p. 7) inclusive deixa claro que nenhuma das teorias possui o monopólio do saber: seja o realismo, sejam as teorias com foco na política doméstica, sejam as teorias que enfatizam as crenças subjetivas, todos têm um papel a desempenhar nas ciências sociais ${ }^{11}$. Hurd (2008, p. 311), por outro lado, ressalta que objetos de estudo do realismo - como prestígio, reputação e hegemonia -, ou do institucionalismo - como a ação interessada - também são considerados pelo construtivismo - ainda que sob outra perspectiva -, possibilitando um estreitamento das fronteiras entre as diversas abordagens, e mesmo dificultando a sua definição em termos exclusivos.

Postos tais termos, parece que qualquer um dos modelos de análise das relações internacionais invocados poderia mesmo justificar a formação dos regimes internacionais sobre restituição de crianças, e, portanto, a cooperação judicial ali envolvida. Resta saber de que modo específico isso acontece.

${ }^{11}$ No original: "No perspective has a monopoly on wisdom: realism, theories focusing on domestic politics, and theories emphasizing subjective beliefs all have a role to play. Contestation between different approaches can play a positive role in social science scholarship, pushing advocates to sharpen their theories and to test them in more convincing ways". 


\section{Cooperação Jurídica em Hipóteses de Remoção ou Retenção Indevida de Crianças e os Modelos de Análise das Relações In- ternacionais}

Não é preciso muito esforço para identificar, tanto na Convenção da Haia de 1980, sobre os Aspectos Civis do Sequestro Internacional de Crianças, quanto na Convenção Interamericana Sobre Restituição Internacional de Menores os elementos conceituais de um regime internacional. Com efeito, ambas foram construídas sobre o princípio do bem-estar do menor, "[...] sujeito de direito que, por suas características especiais, precisa de proteção diferenciada [...]", sem que se o considere propriedade de seus pais (MARTINS, 2013, p. 50); e também são informadas pelo respeito recíproco aos ordenamentos jurídicos de cada um dos Estados-Partes (Estado de Direito), a partir da observância das regras de constituição da custódia ou guarda no país de origem. Dispõem sobre o padrão adequado de comportamento das autoridades judiciais e administrativas diante da remoção ou retenção indevida de crianças. Especificam quais os procedimentos a serem adotados pelos interessados e estabelecem redes cooperativas entre autoridades centrais administrativas e judiciais. Por fim, integram processos coletivos para a formação de consensos, sem os quais não haveria como identificá-las como regimes, diferenciando-as de outras instituições (GONÇALVES; COSTA, 2011, p. 165).

A questão aqui, contudo, não é sua identificação como regimes internacionais, mas a sua justificação como construções de consenso para práticas cooperativas, a partir dos modelos de análise das relações internacionais, nada obstante relações de poder e segurança não surjam imediatamente com a invocação do objeto tratado.

De se observar antes de tudo que a cooperação jurídica internacional consiste

[...] no conjunto de regras internacionais e nacionais que rege atos de colaboração entre Estados, ou mesmo entre Estados e organizações internacionais, com o objetivo de facilitar o acesso à justiça. (RAMOS, 213, p. 624) 
Contempla não apenas o relacionamento entre autoridades judiciárias, mas se estende às Autoridades Centrais administrativas, órgãos responsáveis pela articulação e efetivação do trâmite cooperacional, o que merece o destaque de Arruda (2013, p. 24) quanto à preferência pela expressão "cooperação jurídica internacional", em detrimento de "cooperação judiciária", sob o argumento de que "[...] a efetividade da jurisdição [...] pode depender do intercâmbio não apenas entre órgãos judiciais, mas também entre órgãos administrativos e/ou investigatórios, ou, ainda, entre órgãos judiciais e administrativos [...]"12.

No nosso estudo específico, a cooperação jurídica tem o escopo de localização e acesso à criança subtraída, bem como sua restituição ao Estado de origem, a fim de que seja restabelecida a situação primitiva - nos casos em que esta era adequada - ou identificadas, na prática, as situações excepcionais que justificariam o não retorno.

Diante da perspectiva realista ou estruturalista, alguns poderiam considerar improvável a constituição de regime internacional que comprometesse Estados a proceder à devolução de descendentes de seus nacionais (muitas vezes também nacionais daquele Estado de refúgio) para que disposições sobre a vida privada destes fossem adotadas por órgãos de Estado estranho, ação possivelmente identificada como enfraquecimento do exercício do poder.

Não se pode olvidar, todavia, que para os realistas o equilíbrio do poder em termos políticos também pressupõe "[...] que os Estados agem para impedir que outro Estado desenvolva uma preponderância” (NYE, 2008, p. 80). Nesse caminho, o vínculo cooperacional estudado acabada por certificar a não supremacia indiscriminada de quaisquer atos legislativos ou judiciais - e, portanto, do Poder do Estado - com base apenas em nacionalismos. Considerado o realismo das relações internacionais, os

12 Ramos (2013, p. 625) também defende a propriedade da expressão “cooperação jurídica internacional". Muito embora destaque a pluralidade de locuções utilizadas pelos diferentes Estados -como “cooperação judiciária internacional”, “cooperação judicial internacional, "assistência mútua internacional e "cooperação jurisdicional internacional - afirma que, "[n]o Brasil, há razoável consenso em torno da terminologia 'cooperação jurídica internacional", que seria de maior alcance, ao mesmo tempo em que mais precisa. 
regimes de que se trata se justificam a partir da garantia de um Estado quanto ao não esvaziamento de sua soberania a partir de decisões judiciais proferidas por outros.

Noutra senda, Stephen Krasner (1982, p. 195), por consideração do estruturalismo, invoca o autointeresse egoísta como fator causal básico da formação de regimes internacionais. Ressalta que a preocupação de um ator autointeressado com o comportamento de outros atores se dá apenas na medida em que aquele comportamento pode afetar a utilidade buscada ${ }^{13}$. Ora, a utilidade buscada na situação fática trazida pelo presente estudo é a ineficácia jurídica do transporte ou da retenção indevida de crianças, a fim de desencorajar comportamentos posteriores semelhantes, efeito inverso do alcançado pela ação individual do Estado que, através do seu Poder Judiciário, prestava tutela que conferia ao subtrator a posse do subtraído, sem sequer considerar o ordenamento jurídico do Estado de origem, a partir do qual direitos de custódia já haviam sido originariamente constituídos.

O estabelecimento de comportamentos estatais recíprocos e homogêneos, neste caso, favorece o alcance da utilidade buscada por cada um dos integrantes do regime, na medida em que estabelece um padrão de confiança entre Estados no sentido de que cada um dos Poderes Judiciários respectivos prezará pela restituição da criança, sem decidir sobre questões de guarda esvaziando, assim, a pretendida alteração artificial da competência. Evita-se aí que o Poder Judiciário ao qual é feito o pedido de restituição lance mão da mera simpatia para com os nacionais do Estado que representa, agindo com respeito às disposições convencionais.

Nye (2008, p. 85), outrossim, invoca o conceito de equilíbrio do poder como um sistema multipolar, para justificar que as alianças são também constituídas para "assegurar a segurança mútua". De fato, pactos específicos não relacionados diretamente a questões de poder possuem o efeito indireto de alterar o portfólio de "nações amigas" e reduzir o risco de agressões armadas, além de favorecer a possibilidade de futuras alianças militares ou para alcance de utilidades outras relacionadas ao poder econômico.

\footnotetext{
${ }^{13}$ No original: "The egoist is concerned with the behavior of others only insofar as that behavior can affect the egoist's utility".
} 
Num outro giro, uma ótica institucionalista demonstra que a cooperação em situações como a disposta pode estabelecer a confiança entre o Estado de origem e o Estado de refúgio, ao traçar padrões de decisão que serão adotados por todas as autoridades administrativas e judiciárias envolvidas; pode aprimorar o fluxo comunicativo, essencial para a localização do subtrator e da criança; pode reduzir os custos de acesso ao Poder Judiciário dos Estados-Partes por estratégias de justiça gratuita e de patrocínio público de ações judiciais; pode também reforçar o custo da traição pelo risco de se ver, em situação posterior, submetido ao mesmo tratamento dispensado àquele que havia sido anteriormente traído (retaliação); e pode afastar a má reputação de Estado de asilo de subtratores ilegais.

Por fim, numa perspectiva construtivista o que se pressupõe é que que a formação dos regimes em questão se deu não somente a partir da estrutura política já posta, mas a partir do conteúdo axiomático social de comunidades que compartilham valores de proteção a crianças e prezam pela independência da jurisdição e pelo Estado de Direito.

Perceba-se que se trata aqui de instituições de Direito Civil, cuja "impraticabilidade de direcionar em sentido uniforme" é destacada por Dolinger (2011, p. 166), na medida em que "dependentes em cada país de antecedentes, tradições, influências e necessidades diversas". Nesse sentido, a existência de ordenamentos compostos a partir de valores sociais nem sempre convergentes estimulou a conduta do subtrator e, portanto, a formação de regime internacional com vistas à neutralização de tal conduta.

Tenha-se, por outro lado, que o conhecimento acerca dos limites da guarda ou custódia em cada um dos ordenamentos jurídicos dos Estados-Partes é importante para definir se o transporte ou a retenção foram de fato indevidas; ou que as técnicas policiais de localização de pessoas desaparecidas são importantes para garantir o direito de acesso também previsto pelas convenções. Nesse sentido, o conhecimento acerca das práticas empreendidas por cada um dos atores finda por subsidiar a manutenção e o fortalecimento dos regimes internacionais sobre restituição de crianças.

Diante de tais termos, parecem justificadas as bases de constituição e desenvolvimento dos regimes internacionais aqui tratados, com base nos modelos de análise das relações internacionais. E mais: resta funda- 
mentada a cooperação internacional, ainda que sob pressupostos realistas ou estruturalistas, em hipóteses nas quais se passa apenas à margem de questões de poder e segurança militar.

\section{Conclusão}

Mesmo diante do pessimismo realista ou estruturalista que afasta da zona de interesse dos Estados quaisquer questões não relacionadas ao poder, a teoria das relações internacionais, inclusive por outros modelos de análise, tem dado provas de que cooperação é possível e inclusive desejável.

Nesse contexto, mesmo as matérias relacionadas ao Direito Internacional Privado se inserem na agenda da cooperação e se constituem em objeto de regimes internacionais, como o são aqueles formados a partir da Convenção da Haia de 1980 sobre os Aspectos Civis do Sequestro Internacional de Crianças e a Convenção Interamericana Sobre Restituição Internacional de Menores, inteiramente adequados à base conceitual e teórica disposta.

Até mesmo o mainstream da teoria dos regimes, também denominado institucionalismo neoliberal, que compartilha muitas bases teóricas com o realismo, pode se adequar à ideia de regimes sobre temáticas periféricas como instrumentos de fortalecimento dos alicerces da cooperação, criando canais de informação confiável e de menor custo, assim como incrementando custos de traição. É, porém, dentre as tendências que reconhecem as instituições como constitutivas de processos mais amplos da construção de termos compartilhados que baseiam e balizam as relações entre atores internacionais, como o cognitivismo moderado e o construtivismo, que a relativa marginalidade das temáticas de cooperação judicial se reposiciona, enfatizando o caráter fundante e central de meios difusos de cooperação e atuação conjunta como estruturantes e articuladores de relações e, portanto, essenciais para a formação de consensos em torno de conceitos e valores; aproximando percepções de identidade sobrepostas, não necessariamente estanques ou conflitantes. 
Relevante notar que ainda que no caso dos regimes estudados se possa aplicar a noção de simetria - com a pressuposição de que todos os atores possuem interesses semelhantes - pelo que se poderia supor que se trata de simples questão de coordenação, o que se destaca é que a atuação individual incrementa o risco de se alcançarem resultados inadequados ${ }^{14}$, bem como reduz as possibilidades de contenção do poder do outro, assim como o contexto favorável a futuras alianças, inclusive militares, pelo que justificada a aplicação dos modelos teóricos das relações internacionais para respaldar a formação de regimes não diretamente relacionados a questões de segurança e poder.

\section{Referências}

ARRUDA, Vivian Anne Fraga do Nascimento. Cooperação Jurídica no Combate aos Cartéis Transfronteiriços: a experiência brasileira e reflexões para o seu aperfeiçoamento. 2013. 207 f. Dissertação (Mestrado) - Faculdade de Direito da Universidade de São Paulo, São Paulo, 2013.

COSTA, José Augusto Fontoura. Breve Análise da Convenção Interamericana para Restituição Internacional de Menores. In: CASELLA, Paulo Borba; ARAÚJO, Nádia (coordenadores). Integração Jurídica Interamericana: as convenções interamericanas de Direito Internacional Privado (CIDIPs) e o direito brasileiro. São Paulo: LTr, 1998. p. 537-563.

DOLINGER, Jacob. Direito Internacional Privado. 10. Ed. revista e atualizada. Rio de Janeiro: Forense, 2011.

GILPIN, Robert. War and Change in World Politics. Cambridge: Cambridge University Press, 1981.

${ }^{14}$ É possível aqui fazer menção a um esquema de jogo denominado de caça ao gamo, no qual, em uma matriz de dois jogadores, ambos podem caçar juntos um gamo (animal maior) ou individualmente uma lebre, restando claro que o alcance do gamo depende da cooperação e que, rompendo-se o trabalho conjunto, há sempre o risco de que algum dos jogadores opte por caçar sozinho a lebre (GONÇALVES; COSTA, 2011, p. 181). 
GONÇALVES, Alcindo; COSTA, José Augusto Fontoura. Governança Global e Regimes Internacionais. São Paulo: Almedina, 2011.

HURD, Ian. Constructivism. In: REUS-SMIT, Christian; SNIDAL, Duncan (Org.). The Oxford handbook of international relations. Oxford: Oxford University Press, 2008. p. 317-326.

KEOHANE, Robert. O. Power and Governance in a Partially Globalized World. London: Rouledge, 2002. Disponível em: <https:// www.questia.com/read/108104469/institutions-law-and-governance-in-apartially-globaized>. Acesso em: 17 nov. 2014.

KRASNER, Stephen. Structural Causes and Regime Consequences: Regimes as Intervening Variables. International Organization, Cambridge, v. 36, n. 2, p. 185-205, Spring,1982. Disponível em: $<$ http://www.jstor.org/discover/10.2307/2706520?uid=2134\&uid=2 $482031273 \&$ uid $=2 \&$ uid $=70 \&$ uid $=3 \&$ uid $=60 \&$ uid $=2482031263 \&$ s $\mathrm{id}=21105212266363>$. Acesso em: 15 nov. 2014.

MARTINS, Natália Gamba. Subtração Internacional de Crianças: as exceções à obrigação de retorno previstas na Convenção da Haia de 1980 sobre os aspectos do sequestro internacional de crianças - interpretação judicial da adaptação da criança. 1. ed. Curitiba: CRV, 2013.

MORGENTHAU, Hans J. A política entre as nações: a luta pela guerra e pela paz. Brasília, DF: Editora Universidade de Brasília/Instituto de Pesquisa de Relações Internacionais; São Paulo: Imprensa Oficial do Estado de São Paulo, 2003. Disponível em: <http://funag.gov.br/loja/ download/0179_politica_entre_as_nacoes.pdf $>$. Acesso em: 17 nov. 2014.

NYE Jr., Joseph S. Cooperação e Conflito nas Relações

Internacionais. Tradução Henrique Amat Rêgo Monteiro. São Paulo: Editora Gente, 2009.

PÉREZ-VERA, Elisa. Explanatory Report on the 1980 Hague Child Abduction Convention, 1981. Disponível em: <http://www.hcch.net/ upload/expl28.pdf>. Acesso em: 12 nov. 2014. 
RAMOS, André de Carvalho. O Novo Direito Internacional Privado e o Conflito de Fontes na Cooperação Jurídica Internacional. Revista da Faculdade de Direito, [S.l.], v. 108, p. 621-647, 2013. Disponível em: $<$ http://dx.doi.org/10.11606/issn.2318-8235.v108i0p621-647>. Acesso em: 11 nov. 2014.

RUGGIE, John Gerard. International Responses to Technology: concepts and trends, International Organization, [S.l.], v. 29, n. 3, p. 557-583, Summer, 1975.

STEIN, Arthur A. Why Nations Cooperate: circumstance and choice in international relations. Ithaca: Cornell University Press, 1990.

. The Etics of Neoliberal institutionalism. In: REUS-SMIT, Christian; SNIDAL, Duncan (Org.). The Oxford Handbook of International Relations. Oxford: Oxford University Press, 2008. p. 222-233.

WOHLFORTH, William C. Realism. In: REUS-SMIT, Christian; SNIDAL, Duncan (Org.). The Oxford Handbook of International Relations. Oxford: Oxford University Press, 2008. p. 131-149.

Rachel de Oliveira Lopes é mestranda em Direito Internacional pela Universidade Católica de Santos (Unisantos), membro do grupo de pesquisas Governança Global e Regimes Internacionais da Unisantos, especialista em Direito Público pela Universidade de Brasília (UnB), especialista em Direito Processual Civil pela Pontifícia Universidade Católica de São Paulo (PUC/São Paulo); Procuradora Federal.

E-mail: rachel_lopes@yahoo.com.br.

Endereço Profissional: Procuradoria Seccional Federal em Santos, av. Pedro Lessa, n. 1.930, Aparecida, Santos, SP. Brasil. CEP 11025-002.

José Augusto Fontoura Costa é doutor em Direito Internacional pela Universidade de São Paulo, possui aperfeiçoamento em UN and Globalization pela Central Europe University, é professor associado na Universidade de São Paulo (USP), professor titular da Faculdade de Direito de Sorocaba. 
E-mail: jafontouracosta@gmail.com.

Endereço Profissional: Universidade de São Paulo, Faculdade de Direito, Departamento de Direito Internacional, Largo São Francisco, n. 95, $7^{\circ}$ andar do Prédio Anexo - DIN Sé, São Paulo. SP, Brasil. CEP 01005-010. 